\title{
INHIBITORY EFFECT OF p-CHLOROPHENYLALANINE ON THE SEXUAL MATURATION OF FEMALE RATS
}

\author{
A. B. FAJER,* D. HOFFMAN* AND E. SHILLITO $\dagger$
}

*Department of Physiology, School of Medicine, University of Maryland, Baltimore, U.S.A., and †Institute of Animal Physiology, A.R.C., Babraham, Cambridge, England

(Received 9th February 1970)

Since Robson \& Botros (1961) described the inhibitory effect of 5-hydroxytryptamine (5-HT) on the sexual development of mice, the hypothalamus has been postulated as a possible site for the action of the exogenous 5-HT. In the rat, introduction of serotonin directly into the third ventricle prevented maturation in normal female animals (Corbin \& Schottelius, 1961) and delayed vaginal opening from an average of 39.7 to 47.6 days (O'Steen, 1965) when administered to young animals.

Koe \& Weissman (1966) have established that parachlorophenylalanine (p-CPA) markedly lowers the concentration of 5-HT in brain and other tissues and that, in brain, there is only a slight decrease in the levels of norepinephrine.

The investigation reported here was designed to determine if the depletion of $5-\mathrm{HT}$ in the brain caused by p-CPA would cause effects which differed from those caused by $5-\mathrm{HT}$ administration.

Sprague-Dawley female rats, 25 days old, were injected intraperitoneally three times weekly with a suspension of p-CPA in $1 \%$ aqueous solution of Tween-80. The concentrations were $316 \mathrm{mg} / \mathrm{kg}$ body weight for the first injection and $100 \mathrm{mg} / \mathrm{kg}$ body weight for the other two and they were adjusted weekly for the changes in body weight. The animals were kept in a $14 \mathrm{hr}$ light $10 \mathrm{hr}$ dark schedule and were freely supplied with laboratory chow and water. Vaginal openings were observed daily and vaginal smears were made after opening had occurred. A total of ninety animals, forty of which served as controls, were used in four series of experiments.

The animals in all groups showed vaginal openings between 36 and 38 days of age. However, there was a great difference in the time taken by the two groups to reach maturity.

As shown in Text-fig. 1 , it took $2 \cdot 7 \pm 0 \cdot 25$ days (mean \pm S.E.) for $50 \%$ of the control animals and $8 \cdot 0 \pm 0.70$ days for $50 \%$ of the treated animals to show a vaginal opening. Cycles were shown by $95 \%$ of the control animals after $6.5 \pm$ $0 \cdot 15$ days while the treated animals took $12 \cdot 7 \pm 0 \cdot 12$ days to reach the same point.

These results show that a depletion of the brain stores of 5-HT may delay maturation of female rats in the same way that was previously described for 5-HT administration. This would indicate that disruption of physiological variations in 5-HT concentration in the hypothalamus or other brain regions (Quay, 1968) may be more important than the absolute changes achieved by depletion or administration of 5-HT. 


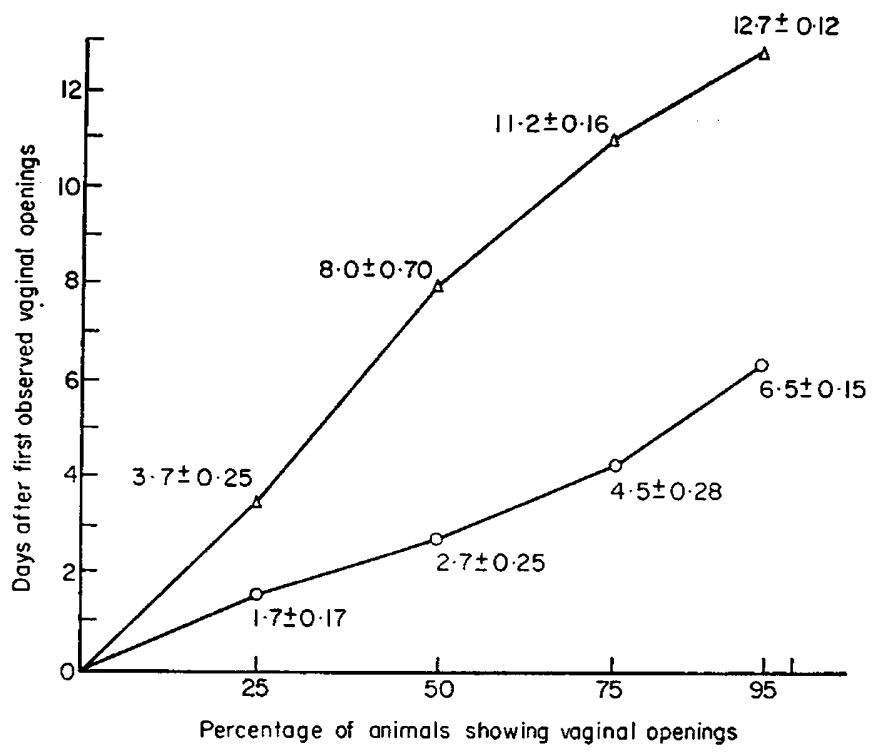

TEXT-FIG. 1. Percentage of animals showing vaginal openings at various times after first observed vaginal openings in the group. $O$, Control animals; $\Delta$, p-CPA treated animals. The figures by each point represent mean values (in days) \pm S.E.

\section{REFERENCES}

Corkin, A. \& Schorreurus, B. A. (1961) Hypothalamic neurohormonal agents and sexual maturation of immature female rats. Am. F. Physiol. 201, 1176.

KoE, B. L. \& Weissman, A. (1966) p-Chlorophenylalanine: a specific depletor of brain serotonin. 7. Phamac. exp. Ther. 154, 499.

O'StEen, W. K. (1965) Suppression of luteinization with serotonin: Further studies on the rat ovary. Anat. Rec. 151, 396.

QUAY, W. B. (1968) Differences in circadian rhythms in 5-hydroxytryptamine according to brain region. Am. F. Physiol. 215, 1448.

Robson, J. M. \& Botros, M. (1961) The effect of 5-hydroxytryptamine and of monoaminoxidase inhibitors on sexual maturity. F. Endocr. 22, 165. 